\title{
3. Waves of transnational solidarity organisations in times of crises: actions, obstacles and opportunities in Europe
}

\author{
Maria Kousis, Angelos Loukakis, \\ Maria Paschou and Christian Lahusen
}

\subsection{INTRODUCTION}

Although transnational solidarity organisations have a long history and cover a wide repertoire of activities (Davies, 2016), there is a lack of upto-date empirical, systematic and cross-national studies on Europe. This is particularly true when examining recent transnational solidarity activism in fields exposed to severe alterations and grievances, such as migration and unemployment. This analysis is overdue and promises important insights, given the recent crises that have affected the European Union and its member states and have thus spurred solidarity activities to a considerable extent. In fact, the financial and refugee crises of the past decade have witnessed the rise of solidarity organisations within and beyond national boundaries, including citizen initiatives, producer-consumer networks, time banks, cooperatives, NGOs, volunteer organisations, social movement groups/organisations, and unions. Such organisations often surface in response to hard economic times (Moulaert and Ailenei, 2005; Kousis and Paschou, 2017; Kousis, Kalogeraki and Cristancho, 2018), but are likely to sustain their activities for groups in need also in less turbulent periods.

The recent refugee crisis of 2015 has accentuated the importance and growth of transnational solidarity organisations. Contentious as well as solidarity movements across the globe, which address refugee and migrant needs, are an important and growing form of a social movement, in need of scholarly attention (Ataç et al., 2016), as they challenge political actors and publicly voice their demands. Older movements, such as the unemployment and labour movements, also illustrate the importance 
of transnational solidarity and the impact of the crisis. Yet, disability activism studies usually focus on the national level (Soldatic and Grech, 2014; Hande and Kelly, 2015). By contrast, recent work on transnational unemployment/labour solidarity addresses its global dimension outside of the European context (McCallum, 2013; Scipes, 2016), as well as within Europe (Lahusen, 2013; Baglioni and Giugni, 2014). Nevertheless, there is a dearth of systematic empirical, cross-national studies on transnational solidarity organisations in these three fields, for the recent crises, with a few exceptions (Kanellopoulos et al., 2018; Loukakis and Maggini, 2018; Zschache et al., 2018).

This chapter's overarching aim is to provide empirical evidence about the development and profile of citizens' collective solidarity mobilisations. ${ }^{1}$ It wishes to address a question that has captured the attention of scholars of social movements and civil societies alike: When, where and how do collective forms of action in support of deprived groups emerge? Moreover, given our interest in transnational solidarity, we can rephrase this question: When, where and how do organised forms of transnational solidarity emerge in Europe? Previous research has provided rich insights into these questions, primarily by highlighting the relevance of two supportive factors: the existence of grievances within the environment in which citizens, civil society organisations and social movements operate, and the existence of resources upon which these citizens, groups and organisations can tap. Social movement scholars have tended to place more weight on resources and organisational capacities, arguing that grievances are a necessary but not sufficient condition for arousing collective action (McCarthy and Zald, 1977; Edwards and McCarthy, 2004; Kriesi et al., 2007). Ultimately, the mobilisation and organisation of collective (solidarity) action depends on the retrieval and assemblage of resources and other organisational capacities. In this chapter, we wish to combine both strands of reasoning, because both are essential to understand the dynamism of solidarity activism and its scope of action. In fact, if we want to understand the formation and expansion of organised transnational solidarity activism in times of crises, we need to point to the mobilising force of external social grievances (a 'pull-factor') and of internal resources (a 'push-factor').

The chapter draws on data on organisations and practices of transnational solidarity, such as citizens' initiatives and networks of cooperation among civil society actors. Such initiatives appear to have become especially visible in the past few years owing to the strong impact of the economic crisis following the drastic cuts in social services and heavy losses in income and jobs (Kousis et al., 2017). Data is available for three different issue fields: migration, unemployment, and disability. The first two fields were included in the analysis because they have been severely affected by 
the economic and financial crisis since 2009 and the so-called refugee crisis of 2015-16, while the field of disabilities seems to have been affected indirectly. The chapter uses a random sample of 2,408 Transnational Solidarity Organisations (TSOs) deriving from Action Organisation Analysis (AOA) (Kousis, Giugni and Lahusen, 2018), as well as an online-based survey sent to 1,108 TSO representatives (TransSOL, 2016).

The chapter will present the empirical evidence in different steps. After introducing the methods and the data upon which this analysis is based, we will deal with longitudinal and cross-sectional analyses. On the one hand, we will present descriptive evidence on the diachronic waves of organised solidarity activism during crises, by field and country, in order to corroborate that the evolution of the field of TSOs at several levels of action (local, national and European) is strongly driven by grievances within specific contexts. On the other hand, we will present the findings of an explanatory analysis of TSOs that is geared to identify those factors that tend to promote and/or inhibit transnational solidarity action in its European scope. This section will be helpful in identifying those organisational capacities that seem to enable waves of cross-national solidarity mobilisation. Finally, the chapter will address also the social and political constraints, within which TSOs and transnational activism have to subsist. It provides insights into the opportunities and constraints that facilitate or challenge solidarity work. The main findings are, finally, discussed in the concluding section.

\subsection{THE METHODOLOGICAL APPROACH}

The empirical study of citizens' initiatives and organisations is a challenging venture, given the informality of many of these groups and the flexibility and fluidity of the organisational field as a whole. With the aim of mapping this field in a reliable and encompassing manner, we had to develop methodological and empirical instruments that are able to paint an authentic picture of these fields in all countries under study. For this purpose, the TransSOL project developed and applied tools to study TSOs through Action Organisation Analysis (AOA) and a web-based survey of highly visible TSOs, ${ }^{2}$ as described below.

\subsubsection{Action Organisation Analysis}

The unit of analysis applied under AOA is the innovative transnational solidarity initiative/organisation (TSO), a specific formal or informal group of initiators/organisers who act in the public sphere 
through solidarity events with visible beneficiaries and claims on their economic and social wellbeing - including basic needs, health, and work - as depicted through the TSO website/online sources (TransSOL, 2016; Kousis, Giugni and Lahusen, 2018). Innovative solidarity reflects responses to actual social everyday challenges, mostly via direct action, in times of crises and embracing online means to promote their cause. According to our criteria of selection, organisations are 'transnational' in terms of at least one of the following categories: (a) organisers with at least one organiser from another country, or supranational agency, (b) actions synchronised or coordinated in at least one other country, (c) beneficiaries with at least one beneficiary group from another country, (d) participants/supporters with at least one participating or supporting group from another country, (e) partners/collaborating groups with at least one from another country, (f) sponsors, with at least one from another country or a supranational agency (e.g. European Regional Development Fund (ERDF), European Social Fund (ESF)), (g) frames with cross-national reference/s, (h) volunteers with at least one volunteer group from another country and (i) spatial, at least across two countries (at the local, regional or national level).

Excluded from the random sample are organisations which were: (1) irrelevant to our three fields and devoted to other areas of work (e.g. elderly care, child care), (2) exclusively organised (or led) by the state, or the EU, or private corporations, (3) non-solidarity oriented, and (4) with a non-transnational, purely local/national orientation, i.e. without any of the nine transnational features (a)-(i) mentioned above (TransSOL, 2016; Kousis, Giugni and Lahusen, 2018).

The randomly selected TSOs are solidarity-oriented in terms of at least one of the following categories: (a) mutual-help, mobilising or collaborating for common interests (bottom-up, solidarity exchange within group), (b) support or assistance between groups, (c) help or offer of support to others and (d) distribution of goods and services to others (top-down, solidarity from above). Second, we were interested in 'innovative' groups insofar as their solidarity work was responding to actual social challenges, and they were engaged in communication via the Internet. Third, our aim was to map the field of solidarity work with these target groups in its transnational dimension. For this purpose, we opted for an inclusive sampling strategy that is not only interested in civic groups directly engaged in 'transnational solidarity', but also open to all organisations indirectly tied into this sector via their partners, supporters or beneficiaries. This sample allows those factors that distinguish the degree of involvement into transnational solidarity work to be identified. Our sampling process yielded 2,408 randomly selected cases (300 in each country, 100 for each 
field). These cases then entered the next stage in the research process, namely coding.

\subsubsection{Online Organisational Survey}

Aiming to shed more light on TSOs based on the views of their representatives, a targeted sample of 1,108 high-visibility TSOs was constructed following systematic Google searches. The web-based survey was conducted in May and July 2016, and involved organisations, groups and networks organising transnational solidarity actions mostly related to the three fields, but also to similar ones (TransSOL, 2016). Following a cycle of reminders, a total of $144 \mathrm{TSO}$ representatives participated in the online survey, leading to an average response rate of $13 \%$ by the end of July 2015 , when the survey closed (this response rate is not uncommon in organisational surveys).

The questionnaire offers detailed information on the mechanisms, activities and links of the involved collective actors, the ways in which they address transnational solidarity with people confronting hardships, and the different types of required resources (TransSOL, 2016).

\subsection{PORTRAYING TRANSNATIONAL SOLIDARITY ORGANISATIONS: A DESCRIPTIVE ACCOUNT OF SOLIDARITY WAVES DURING HARD TIMES}

The methodologies developed allowed us to gather empirical data that paints a diachronic portrayal of TSOs, the spectrum of the solidarity activities they engage in, and the conditions that influence their development. The data not only provides a clear overview of the major characteristics of solidarity groups and organisations, but also sheds new light on their exposure to grievances linked to the different crises of the past decade. In general terms, the data show that TSOs tend to respond to upcoming and pressing grievances. In fact, the evolution of the organisational field is uneven across countries and issue fields, depending on where and how grievances emerge more severely.

\subsubsection{Who Are the Innovating TSOs? Types, Starting Year and Actions}

Our data help to delineate the types of TSOs involved in transnational solidarity. Based on our examination, we find (Figure 3.1) that overall NGOs are the most frequent actor, as seen in almost half $(46.3 \%)$ of all TSOs. This is a non-surprising finding as similar studies have shown that 


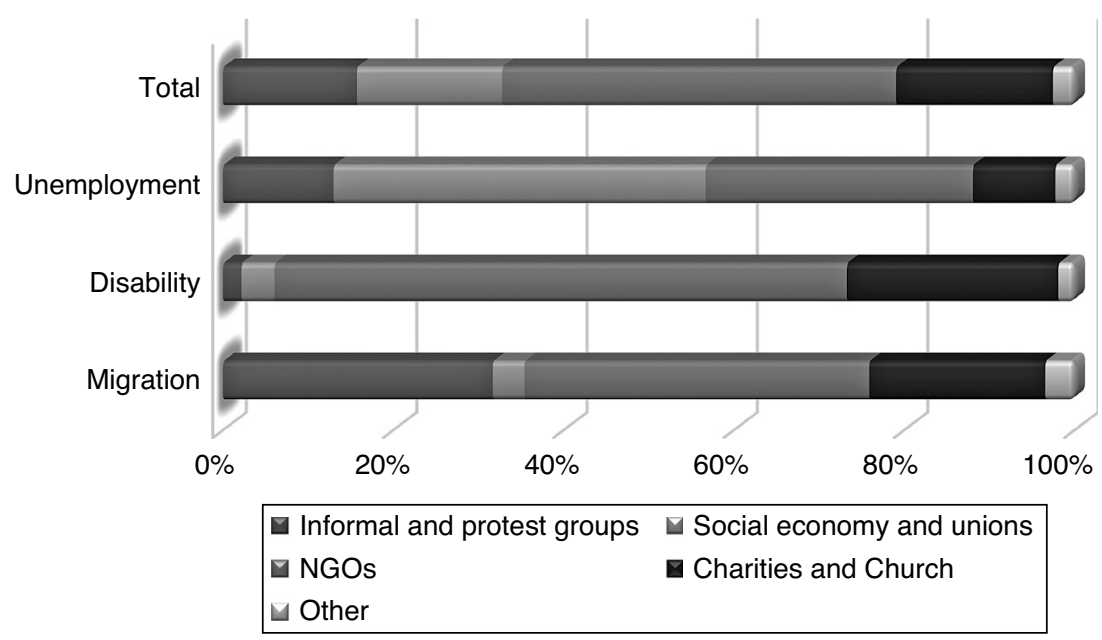

Figure 3.1 Type of TSOs per field

European civil society is dominated by formal humanitarian organisations such as NGOs (Warleigh, 2001; Lahusen et al., 2018). Other expected significant solidarity providers are the Church and charities as well as social economy enterprises and unions (18.4\% and 17.0\%, respectively). While unions are an expected actor - as solidarity is the most promoted value of the workers' movements from the late nineteenth century - the appearance of social economy enterprises is a later development. Social and solidarity economy TSOs also promote equality and rights for the unemployed, people with disabilities and migrants, especially during hard times, and offer an alternative to the dominant capitalist modes of production and consumption.

This picture changes when examining the types of organisations across our three TSO fields. In the unemployment field, the prominent type of TSOs is that of social economy enterprises and unions (43.7\%) - an expected finding as unions are organisations centring on offering solidarity to unemployed or precarious workers. Moreover, there are also NGOs which are mostly oriented towards solidarity services to unemployed people, as well as informal and social movement/protest groups which are mostly active in street politics. Similarly in the disability field, NGOs maintain the leading position, not only engaging in solidarity actions, but also advocating for the rights of people with disabilities in national and EU policy arenas. Finally, in the migration field, solidarity is provided by a very interesting combination of formal and informal TSOs. More specifically, informal citizen and protest groups are very important solidarity 
providers in the migration field as they comprise almost one third of the migration TSOs. This finding strongly reflects the grassroots solidarity offered by local communities that mobilised as a response to the refugee crisis of 2015-16. Informal mobilisation, however, is but one side of the coin, as formal organisations such as NGOs, charities and Churches were equally important solidarity providers during the same period.

\subsubsection{How Does the Organisational Field of Transnational Solidarity Evolve? Depicting Diachronic Waves}

Our data illustrate the diachronic changes within the field of transnational solidarity by making use of the TSOs' starting year. Figures 3.2-3.5 provide an integrated picture of these waves. Looking at the aggregate level that combines TSO data on all eight countries (Figure 3.2), three main findings emerge. First, it is noteworthy that overall, TSOs in the three fields have roots as far back as the early 1900s, with noticeably increasing waves immediately after World War II and the 1950s and 1960s, especially in the unemployment and disability fields. Second, unemployment TSOs and disability TSOs have existed longer than migration TSOs. Third, the top peaks in the numbers of new organisations in the three fields are different: disability organisations were the most numerous from the early 1980s to the early 2000s; unemployment organisations were most widespread from the late 1970s to the early 2010s; and the new migration TSOs escalated in the most recent period, from the 1990s to the present, but with an outstanding peak in the past three years - especially in 2015. Thus, the overall growth of these fields in the eight countries as a whole seems to be concomitant with societal developments. The dynamics tend to reflect the urgency of the various crises affecting the EU, both in terms of accelerating economic downturns and increased rates of immigration.

The picture, however, changes when we disaggregate at the country level by field, as seen in Figures 3.3, 3.4, and 3.5, reflecting different national historical and political-economic contexts. Country differences emerge in the starting year of migration-related TSOs, seen in Figure 3.3. A more even spread with no visible increases in the recent period is seen in Denmark and the UK, in contrast to Germany and Greece with the highest peaks of new TSOs since 2010 and moderate increases in Switzerland and Italy. It is interesting to note that our data reveal earlier peaks in the starting year of TSOs in the 1960s and 1980s for France and Italy, respectively, as well as in the late 1980s and early 1990s in Poland.

Different patterns emerge when looking at disability-related TSOs in Figure 3.4. Compared to the migration ones, the peaks in these newly established TSOs appear in earlier periods and have undergone a decrease 


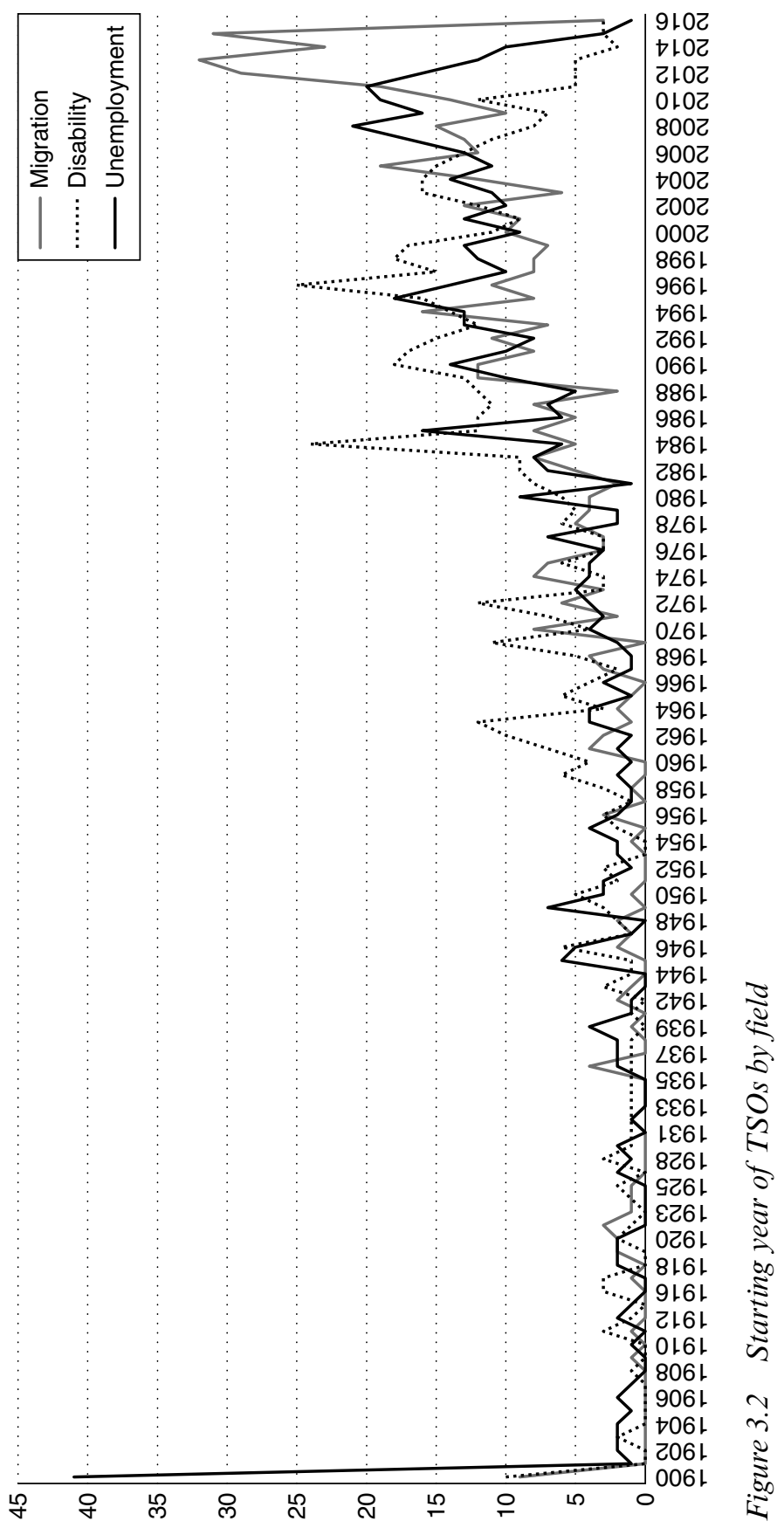




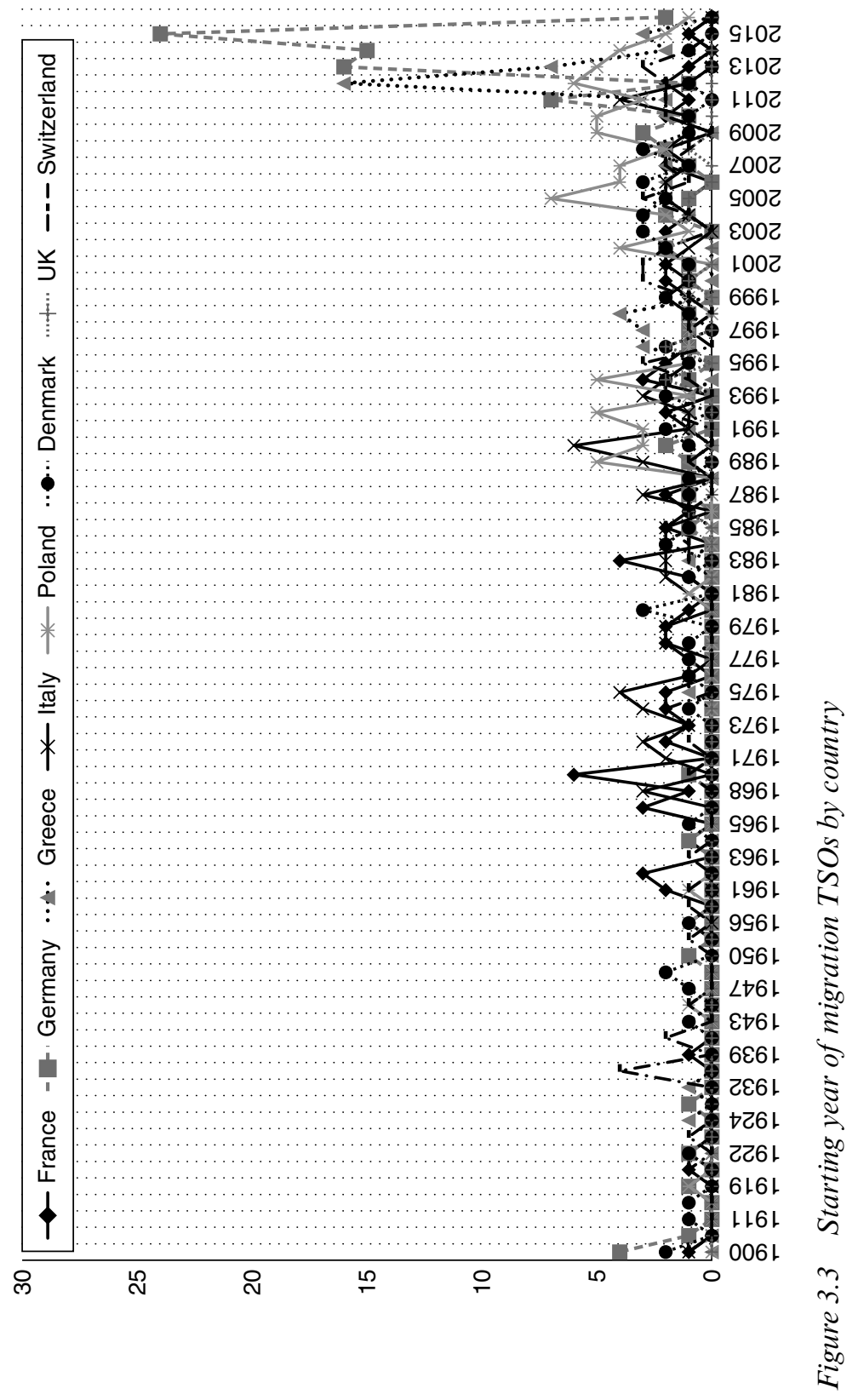




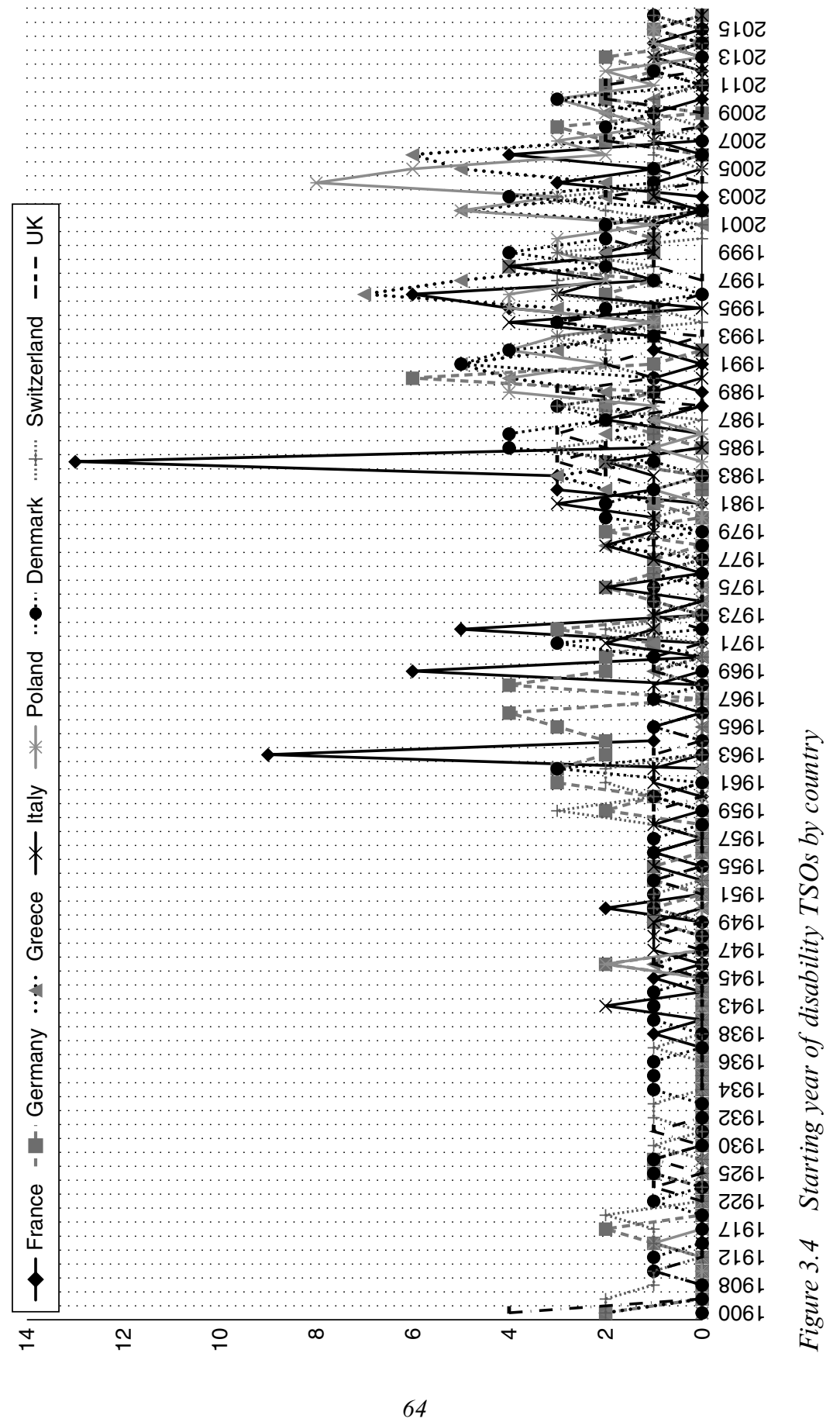




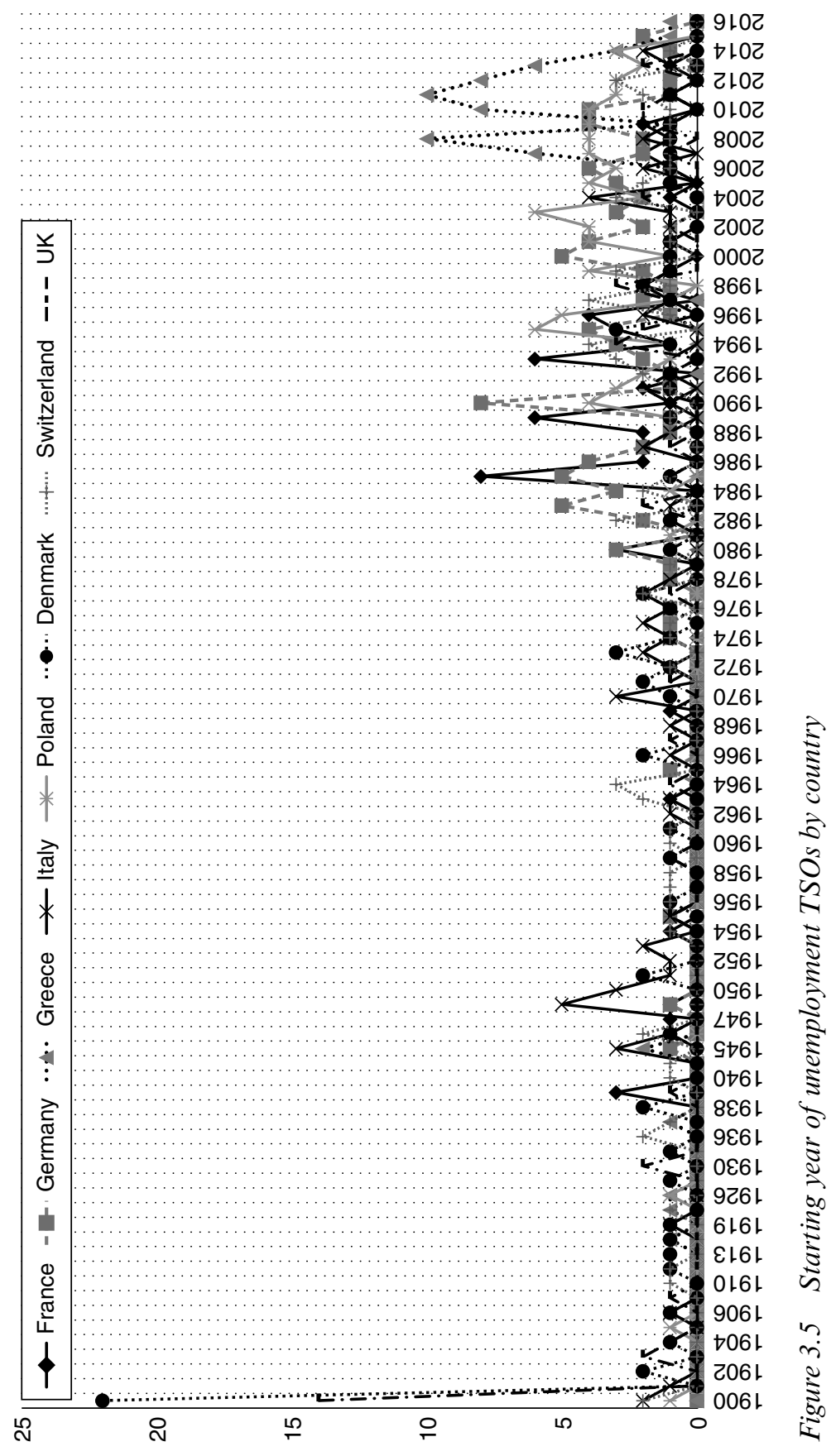


or very slow growth since 2008 . More specifically, significant peaks are visible for France and Germany from the 1960s to the early 1980s, while moderate peaks are seen for the UK, Switzerland, Italy, and Denmark from the 1980s to 2003, but slightly later for Greece and Poland, from the late 1980 s to 2007.

An even more intriguing pattern emerges when examining unemployment-related TSOs in Figure 3.5. These show a longer history, as more of these organisations were established prior to 1900. With the exception of moderate increases in these labour-related TSOs in Italy (1947-53) and Switzerland (early 1960s), a durable growth is seen since the 1980s, with markedly high peaks in France, Germany and Poland. This steady growth, however, has decreased since 2007, with the exception of Greek unemployment TSOs which underwent their highest peaks from 2007 to 2014 - an expected finding in the country with the highest unemployment rate.

To sum up the findings described above, the timelines overall show that different types of crises were always a part of the European social and political reality. Our findings reflect specific moments of 'crises' that augment grievances and thus mobilise organised transnationally oriented solidarity. Thus, we argue that these solidarity mobilisations are closely related to the intensity of the crises. This means that TSO emergence varies depending on national contexts. The more pervasive the impacts of crisis are in a country, the more likely the solidarity mobilisations will be. The most prominent case that supports our argument is that of TSOs in the migration field. Our data clearly illustrate that countries most severely affected by the so-called refugee crisis of 2015-16, such as Greece and Germany, are those witnessing the rise of new TSOs. Similarly, in the unemployment field, peaks in the starting year of the TSOs reflect a crisis of the labour market in different countries. Thus, some countries have the oldest groups (Denmark and the UK), in France and Germany the growth reacts to phases of mass unemployment and mass mobilisation (Lahusen, 2013), and in Greece it reflects the ongoing impacts of the economic crisis since 2010. Finally, illustrating peaks of new TSOs for most of the countries between the late 1980s and early 2000s, the disability field appears to be affected less clearly by the crises of the past decade. The peaks may reflect austerity policies and implementation of cuts in provisions and benefits to their citizens. Overall, our findings indicate that TSOs, especially in the migration and unemployment fields, were established in order to assist those who were left out of state-provided social safety nets. Thus, we could speak of TSOs as Europe's fire brigade, with the subsequent implications this has. 


\subsubsection{Which Transnational Solidarity Activities do Citizens Organise? Addressing Urgent Needs in Local Contexts}

The economic and refugee crises of the past decade that have shaken Europe and left part of the population with unmet needs, are mainly due either to state cuts and austerity policies or decreasing labour market opportunities, especially for migrant/refugee groups. In response to these conditions and the related rise of grievances, many TSOs have organised activities, which mirror the increased demand not only in services, but also in political advocacy.

The spectrum of activities organised by TSOs are seen in Figure 3.6. Overall, most prominent are those activities that are related to urgent needs, i.e. provisions meeting basic daily needs such as food, shelter, clothing, medical services. This is an expected finding, not only for refugees arriving in Europe, but also for people with disabilities facing the consequences of a shrinking welfare state. Next in prominence across the three fields are public sphere dissemination activities which include drafting reports, people's media, raising awareness actions and educational activities for the public. Economy related activities, such as job training programmes, financial support, products and service provision at low prices, fundraising

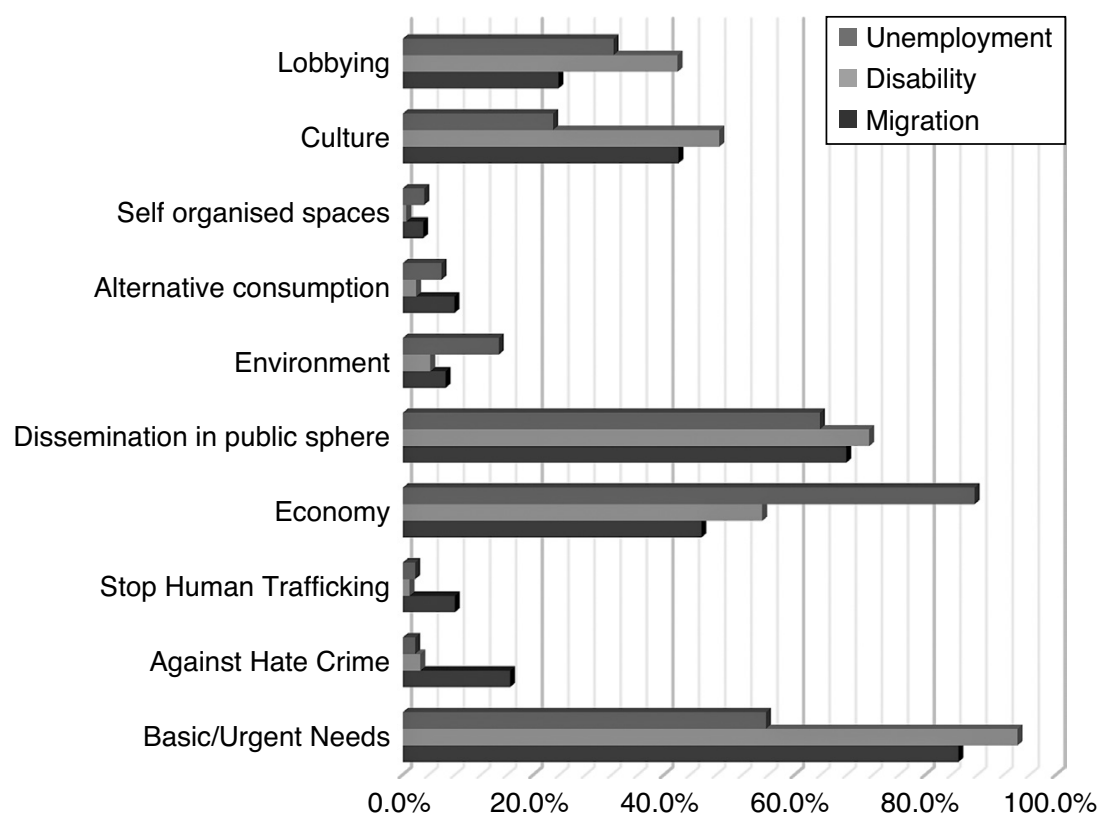

Figure 3.6 Actions of TSOs by field 
activities, second-hand shops and bazaars, as would be expected, are the most prominent activities among unemployment organisations $(87.5 \%)$. A possible explanation of the high frequencies of this category could be the deregulation of labour markets and the rise of the gig economy in European countries as a tool for increasing competitiveness, especially in the Eurozone area. Following in frequency are culture-related (including art, sports and social hangout actions) and lobbying activities. Both are common among TSOs in all three fields, but they are more frequent for disability TSOs (48.4\% and $42 \%$, respectively). With respect to the first, this could be an indication that there is an increased demand for cultural activities, which are, for a significant part of Europeans, related to sociocultural contexts and may be avenues of support for non-cultural activities. Finally, activities against hate crimes and human trafficking can be found especially in migration/refugee-related TSOs, and are most likely linked to the 2015-16 refugee crisis.

The scope of action depicted in Figure 3.7 illustrates that as the frequency of TSOs decreases, the scope of action increases. Thus, citizens' transnational solidarity is mainly manifested at the local level, with more than seven out of ten TSOs being active at this level, irrespective of their field of action. Having in mind that the most prominent action category was that of urgent needs, this finding is possibly an indication that transnational solidarity is mostly expressed in helping specific people in specific circumstances. Moreover, this finding also mirrors the grassroots orientation of transnational solidarity initiatives and social movements as well as an attempt by these initiatives and groups to find collective ways to

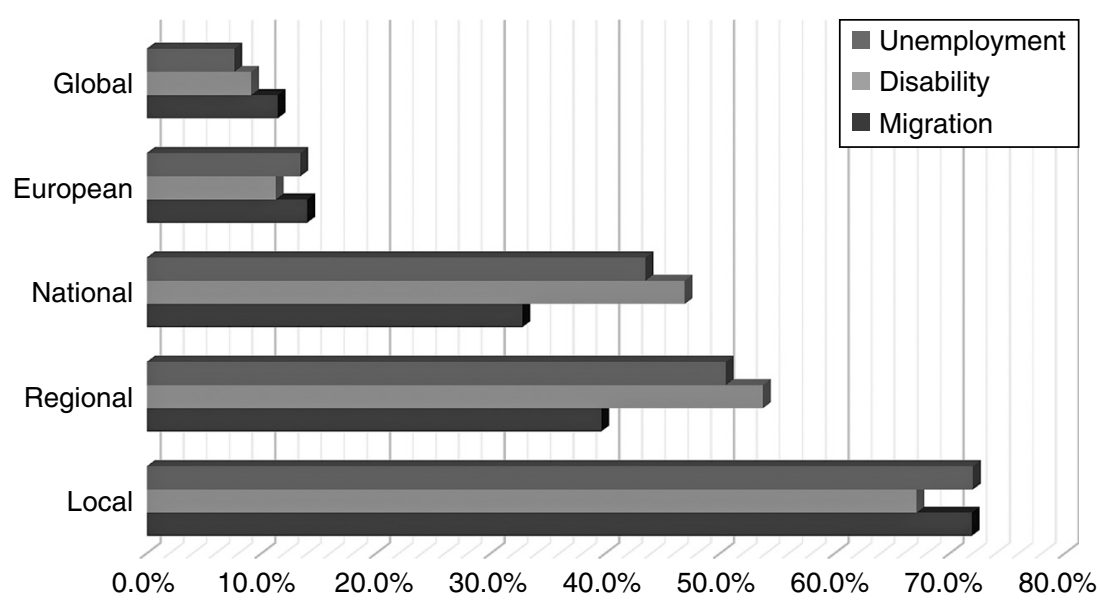

Figure 3.7 The scope of TSO activities by field 
respond to hard times at the local community level. Regional and national level activities are organised by almost $40 \%$ of the TSOs, mostly by those active in the unemployment and disability fields. This may reflect their resourced organisational structures, compared to the local ones. As for the activities beyond borders, these are the less frequent ones, with $13 \%$ of TSOs being active at the EU level and approximately one out of ten at the global level; migration TSOs are more transnationally oriented than the TSOs in the other two fields. The relatively small number of TSOs that organise activities abroad indicates that (a) organising activities beyond the state is an arduous task requiring considerable resources (material, informative, networking and human) which only a few organisations can afford, and (b) the number of people with unmet basic needs has been increasing in European states as a consequence of both the economic and refugee crises of the past decade.

\subsection{UNDERSTANDING THE CONDITIONS OF ORGANISED EUROPEAN SOLIDARITY: THE RELEVANCE OF RESOURCES IN TRIGGERING COLLECTIVE ACTION}

The descriptive account presented above has given first indications that organised forms of transnational solidarity are driven by external grievances, given the uneven evolution of the field across countries and issuefields. In this section we move to a cross-sectional analysis of the coded website data of 2,408 TSOs in order to highlight those internal factors that tend to promote organised solidarity activism, but here, the focus will be exclusively on the European scope of activity, as this is a more demanding venture. For this purpose, we can make ample use of hypotheses and findings discussed within the literature on civil society organisations and social movements. In this regard, we offer four propositions all of which relate to different forms of organisational capacities: formality, partners and supporters, the age and experience, values and identities, and action repertoires.

\subsubsection{Applying Existing Knowledge to TSOs: Explanatory Factors and Research Assumptions}

Abundant works in the field of organisation and social movements indicate that formality is related to the scope of activities undertaken by organisations. More specifically, Resource Mobilization Theory (RMT) (McCarthy and Zald, 1977; Jenkins, 1983) examines structural factors, 
as well as the availability of the organisation's resources and networks, in order to analyse the emergence of social movements and their characteristics. In general, the most common organisational resources are those of personnel and finances (Edwards and McCarthy, 2004; Kriesi et al., 2007). Thus, previous research has shown that centralised and formally structured organisations mobilise resources and achieve goals more effectively than decentralised and informal groups (Jenkins, 1983; Edwards and McCarthy, 2004). Based on this approach, as similar studies have shown (Lahusen et al., 2018; Loukakis and Maggini, 2018) we can expect that European solidarity is strongly affected by the structure and resources of the organisations we have coded, regardless of their field of activity. Therefore, our first hypothesis is as follows:

H1: European-level activities by TSOs are related to the degree of their formalisation, given that TSOs with higher levels of formality have greater organisational capacity and skills to engage in activities beyond national borders compared to informal groups.

There is also a rich literature in the field of social movements about the importance of networks and partners as factors that foster transnational mobilisation (Imig and Tarrow, 1999; Kousis and Eder, 2001; della Porta and Caiani, 2009). Most of these studies focus on the diffusion of mobilisation and action repertoires from one country to another and the impact of Europeanisation. Other studies, (e.g. Ruzza and Bozzini, 2008) indicate that EU-level associations and networks play a role in the coordination of transnational protest activities. Similarly, in the solidarity mobilisations field, Lahusen et al. (2018) point out that the existence of transnational partners foster the Europeanisation of solidarity. This can be summed up in our second hypothesis:

H2: TSOs that mention EU or its agencies as partners are more likely to engage in European-level activities than those that do not mention EU-related partners.

The economic crisis and austerity measures have reduced funding opportunities for civil society organisations, with funding from both state and private donations becoming unstable and unreliable, while at the same time competition over scarce resources is increasing. A study of the impact of the 2008 economic downturn in the USA on the nonprofit sector suggests that the sector overall experienced declining revenues (Salamon et al., 2009). At the same time, we also know that new organisations face greater risk of failure and are more vulnerable towards changes in their 
environment (McCarthy and Wolfson, 1996). Empirical evidence confirms that older organisations can weather an economic crisis more effectively (i.e. without witnessing a decrease in their financial resources) and more often, compared to the newly established ones (Raffo et al., 2016). Thus, we expect that younger TSOs, which are established during hard economic times, will have fewer resources and, therefore, fewer opportunities to engage in European level activities. To sum up, our third hypothesis is:

H3: TSOs established during the 2008 crisis are less likely to be engaged in European-level activities than the TSOs established before the crisis.

Solidarity as a core element of TSOs' strategic targeting is a broad and multidimensional concept. One can distinguish between a vertical approach and a horizontal approach to solidarity. The former (top-down) focuses on service provision and is largely related to philanthropic values towards helping others; the later (usually bottom-up) is governed by the idea of reciprocity and mutualism (see Uba and Kousis, 2018). Horizontal solidarity is tied to political aims towards the empowerment of communities and social change, while in its scale shift it bears "on fractured and contested political struggles and communities" (Featherstone, 2013: 37-8), being subject to political conflict (Passy, 2001). Hence, the Europeanisation of TSO activity is most likely related to a horizontal approach of solidarity, which prioritises a set of political aims, such as the promotion of universal rights, policy reforms at the European level and transnational networking. Contrary to this, vertical or pragmatic approaches of solidarity are more likely to be tied to particular (proximal or transnational) localities. This leads to the formulation of the following hypothesis:

H4: The adoption of a solidarity orientation grounded on the principle of reciprocity and mutual help is expected to predict engagement in activities at the European level.

Organisations select their action repertoires based on structural conditions (McAdam, 1983) and shifting political opportunities (Tarrow, 1998), their available resources (Freeman, 1979) and their interpretations of the institutional environment in relation to the efficacy of particular forms of action (Carmin and Balser, 2002). Conventional and institutionalised approaches, such as lobbying, litigation and educational practices are more diffused among highly formalised, rationalised and professionalised TSOs (Piven and Cloward, 1977; Staggenborg, 1988; Hwang and Powell, 2009), when compared to those engaged in contentious action repertoires. Added to that, the forms of action employed by organisations are channelled by 
the resources they receive, thus "reflecting the interests of their funders" (Carmin and Balser, 2002: 367; see also McCarthy et al., 1991). Having all these assumptions in mind, we expect that TSOs engaged in conventional action repertoires and strategies such as lobbying, awareness raising and policy change should be more inclined to expand their scope of action towards other countries, as they might count on additional resources and a more supportive political context. Contentious groups will remain more strongly tied to a local or national scope of activities, given that their protests will be linked to specific demands, addressees and constituencies. Based on the above, the final hypothesis is:

H5: TSOs that apply conventional approaches to achieve their goals are more likely to be engaged in European activities than those that use protest as a strategy.

In order to empirically test the theoretical hypotheses we have presented above, we operationalised the relevant factors by means of a number of independent variables that might foster actions with a European scope: degree of formalisation, year of establishment, partnership with EU and its agencies, solidarity approaches, organisational strategies and contextual control variables (countries). Before describing the independent variables, it is necessary to define what we considered TSO engagement in European level actions to be (dependent variable): they reported activity in at least one EU or non-EU European country, and/or they have beneficiaries in at least one other European country (both EU and non-EU), and/or they took part in European-level protest actions, and/or they tried to defend their beneficiary/participants' interests and rights via European courts. Finally, we ran three different logit regression models, one for each field.

Regarding the independent variables, formality is measured through a list of eleven organisational features, i.e. having: a board, president or leader, secretary/administrative assistant, treasurer or someone responsible for finance, trustees, paid staff, a written constitution, spokesperson/ media-PR, general assembly, neighbourhood/open assembly and committees for specific issues. We constructed a composition index based on these features and then divided the TSOs into three categories that measure formality based on their scores in this index: Low (includes the TSOs which scored 0 to 3; it is the reference category), Medium (scores 4 to 6) and High formalised TSOs (scores above 6). Moreover, in order to check the crisis effect on TSO activity, a dummy variable was created based on whether the TSO was founded before (0) or after (1) the financial crisis. The period after 1 January 2008 was defined as the crisis threshold. In order to test whether partnership with EU agencies foster European level activism, we 
merged three variables that measure if TSOs mention Migration- and/ or Disabilities- and/or Unemployment-related European/EU agencies as partners, and we created a new dummy variable which measured if the TSO indicates the EU or its agencies as partners $(0=$ no, $1=$ yes $)$. Regarding the solidarity approaches, there are four possible approaches (from bottom-up to top-down) in our codebook: Mutual help, Support/assistance between groups, Help/offer support to others (altruistic), as well as Distribution of goods and services to others.

Regarding the strategies that the TSOs apply, our codebook specified a number of both conventional and contentious actions. In the specific model we chose, we opted to test the effect of four possible ways by which TSOs try to achieve their goals, using dichotomous variables for (a) protest actions, (b) raising awareness, (c) lobbying, and (d) policy reform (in our codebook there are seven variables that indicate policy change as strategies; we merge these via the and/or command and create a new dichotomous variable).

Finally, our analysis aims to ascertain whether transnational solidarity actions are distributed evenly across countries. For this purpose, we included dummy variables specifying the country (with France as the reference category). The third part of the analysis is also descriptive and it is based on the results of the organisational online survey with 144 representatives of high visibility TSOs operating mostly across borders (TransSOL, 2016). In this part we present the core changes that the organisations felt after the crisis, the increased demands that they faced, as well as the constraints that they had to overcome in order to continue their activities.

\subsubsection{Explanatory Analysis: The Determinants of European-Level Activities across Countries and Issue Fields}

Table 3.1 presents results for all three models, which include odds ratios as well as goodness-of-fit statistics (Nagelkerke pseudo-R-squared values). The explanatory power of all three models is about $25 \%$ to $30 \%$, i.e. satisfactory for organisational data. The analysis shows that only a few factors tend to impact on transnational solidarity activism.

Two hypotheses cannot be validated. Highly formalised TSOs (H1) are slightly more active at the transnational level, but the effect is not statistically significant. Interestingly, TSOs of moderate formality are less likely to be engaged in such activities than the informal TSOs. These findings contradict expectations (Jenkins 1983; Hirsch, 1986; Kriesi et al., 2007), as they indicate that varying degrees of formality are a less decisive factor in predicting engagement in transnational solidarity. Obviously, informal groups are almost as often involved in these activities, probably due to 
Table 3.1 Logit regression models for transnational activities for each field

\begin{tabular}{|c|c|c|c|}
\hline & Migration & Disability & Unemployment \\
\hline \multicolumn{4}{|l|}{ Formality* } \\
\hline Medium & -0.322 & $-0.830^{*}$ & -0.316 \\
\hline High & 0.194 & 0.116 & 0.010 \\
\hline EU partners & $0.779 * *$ & 0.230 & 0.072 \\
\hline Established during crisis & -0.245 & -0.039 & -0.440 \\
\hline Mutual help & -0.322 & $0.512+$ & -0.328 \\
\hline Collaboration & 0.419 & $0.662 *$ & $1.278 * * *$ \\
\hline Altruistic & -0.043 & 0.012 & 0.126 \\
\hline Top down & 0.139 & 0.329 & 0.417 \\
\hline Collective/protest action & -0.499 & 0.047 & $0.868^{*}$ \\
\hline Raise awareness & 0.450 & 0.484 & 0.430 \\
\hline Lobbying & 0.387 & -0.313 & -0.244 \\
\hline Policy reform & $0.743^{*}$ & $1.031 * *$ & $0.758 *$ \\
\hline \multicolumn{4}{|l|}{ Country* } \\
\hline Germany & $-2.699 * * *$ & $1.595^{* *}$ & $1.342 *$ \\
\hline Greece & $-1.617 * *$ & 0.015 & -1.223 \\
\hline Italy & $-2.112 * * *$ & -0.224 & 0.252 \\
\hline Poland & $-0.778+$ & -1.632 & $1.697 * *$ \\
\hline Denmark & $-1.558 * *$ & $1.283^{*}$ & $1.921 * * *$ \\
\hline Switzerland & $-3.787 * * *$ & -0.520 & 0.599 \\
\hline UK & -22.053 & -0.640 & -0.353 \\
\hline Constant & -0.002 & $-3.281 * * *$ & $-3.579 * * *$ \\
\hline pseudo R2 & 0.294 & 0.312 & 0.261 \\
\hline $\mathrm{N}$ & 534 & 636 & 594 \\
\hline
\end{tabular}

Notes:

$+\mathrm{p}=0.1,{ }^{*} \mathrm{p}=0.05,{ }^{* *} \mathrm{p}=0.01, * * * \mathrm{p}=0.001$

*low formality is the referenced category, *France is the reference category

increased grievances across countries. Also, the time of establishment (H3) is not a significant factor. Table 3.1 shows that TSOs active in transnational solidarity are less often established during the crisis, thus conforming to our expectations, but this effect is not statistically significant. This finding may reflect the fact that a considerable share of groups were founded in direct reaction to the crises and were also engaged in transnational solidarity.

A number of organisational factors tend to have a beneficial impact on transnational solidarity actions. The existence of European partners (H2) is positively associated with engagement in European-scope actions, but the effect has only statistical significance for the migration TSOs, thus refuting research assumptions expressed in the literature (Ruzza and Bozzini, 2008; Lahusen et al., 2018; Loukakis and Maggini, 2018). This 
means that TSO engagement is not fully dependent on European partners, as they may react to the immediate calls to action within an environment dictated by grievances.

Solidarity approaches are clearly related to the engagement of TSOs in activities with European scope (H4). In fact, horizontal solidarity orientations (i.e. driven by reciprocity and mutuality) are more likely to lead to European activities, compared to vertical ones (unilateral help provision). In detail, Table 3.1 indicates that only two out of the four solidarity approaches are statistically significant for the European activities of the TSOs. Starting with the mutual help approach, findings show that they increase the likelihood of European engagement only in TSOs active in the disability field while they are negatively associated with the other two fields, yet without being statistically significant. On the other hand, a collaborative solidarity approach increases the odds of European activities engagement for both disability and unemployment TSOs without touching those of the migration field. As for the remaining two solidarity approaches (altruistic and top-down), they do not significantly affect any of the TSOs, regardless of field.

Action repertoires also influence readiness to engage in European solidarity, but they do not corroborate our expectations in all respects. Activities geared towards policy reforms clearly increase the likelihood for European level engagement of TSOs in all three fields. Also protest as a strategy increases the probability of European-level activity, but only among the unemployment TSOs, while it decreases the likelihood for those engaged in the migration field, even though the effect is not statistically significant. This finding is an indication that a contentious action repertoire might be more diffused among specific issue-fields, in this case in the ambit of TSOs addressing unemployment issues. This seems to reflect the impact of labour movements and of labour conflicts in times of accelerated economic crises, the deregulation of labour markets and austerity measures.

Summing up the findings from our explanatory models, the solidarity approach and the repertoire of action seem to be the best predictors, albeit for specific fields. Unemployment and labour-related TSOs are committed to a horizontal understanding of solidarity that involves norms of reciprocity and mutualism and that is linked to more political and contentious activists. This leads them to develop cross-national forms of activism - independently from the question of whether these organisations are formal or informal, new or old. The fact that these organisations have more partners underlines the horizontal approach. Migration TSOs are influenced by their EU partners in carrying out their transnational solidarity activities, and these activities are also driven by a more conventional action repertoire aiming at policy reforms. 


\subsection{STRUGGLING WITH CIRCUMSTANCES: A DESCRIPTIVE ACCOUNT OF CONTEXTUAL OPPORTUNITIES AND CONSTRAINTS FOR TSOs IN TIMES OF CRISES}

Previous findings have shown that organised solidarity activism particularly those activities with a European scope - depends on a number of conditions. In its local, national and European expression it is more probable in contexts marked by collective grievances and urgent needs. With respect to its European scope of activity, it is additionally patterned by organisational capacities and resources. These findings raise questions about the contextual opportunities and constraints that might endanger transnational solidarity activism. To answer this question, we present the findings from the online organisational survey data, as they help to demonstrate with which opportunities and constraints high visibility TSOs have been faced since 2010, under the two crises. Overall, findings document that in times of crises, needs increase but resources are scarce, while constraints increase at the same time. This situation reduces the capacity of TSOs to fulfil their mission effectively.

In terms of funding, Figure 3.8 demonstrates that state funding decreased, while non-state and EU funding increased. EU funding is reported as a stable and reliable funding source unaffected by national austerity policies, which restrict the availability of national funds. Migrationand disability-related TSOs received more funding from non-state sources, while unemployment-related TSOs expressed equal degrees of increases

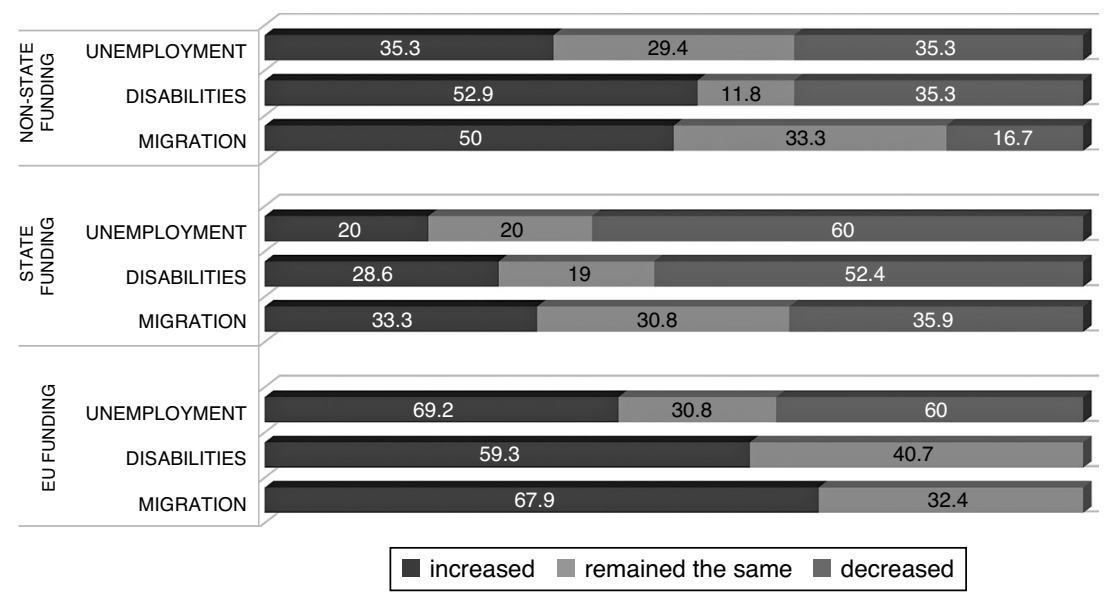

Figure 3.8 Experienced changes in funding sources, by field 
and decreases in non-state funding. As for state funding, more than half of unemployment and disability TSOs experienced a decrease, while for migration TSOs, there is a balance in their responses on the direction of change. In regard to EU funding, none of the migration TSOs faced decreases in EU funding, while in addition, the majority of TSOs in the field of disability and unemployment experienced an increase. These findings might reflect changing funding opportunities: while national funding seems to be on the retreat, possibly as a reaction to the economic crisis and austerity measures, EU funding becomes a more important source. Thus, our findings provide further evidence for the detrimental effects of the economic recession on the operation of civil society organisations (Pape et al., 2016), but most importantly on their Europeanisation, with respect to funding due to budget cuts at the national level in the context of the eurozone crisis (Sanchez Salgado, 2017). In addition, the relatively higher levels in the increase of funding reported by migration organisations relates to their involvement in the management of the recent refugee crisis (Feischmidt et al., 2019).

As for the changes related to the action repertoires of the TSOs and the frequency of their actions, Figure 3.9 shows that needs have increased with a simultaneous increase in the number of TSO beneficiaries or participants. At the same time, TSOs try to conduct more activities in

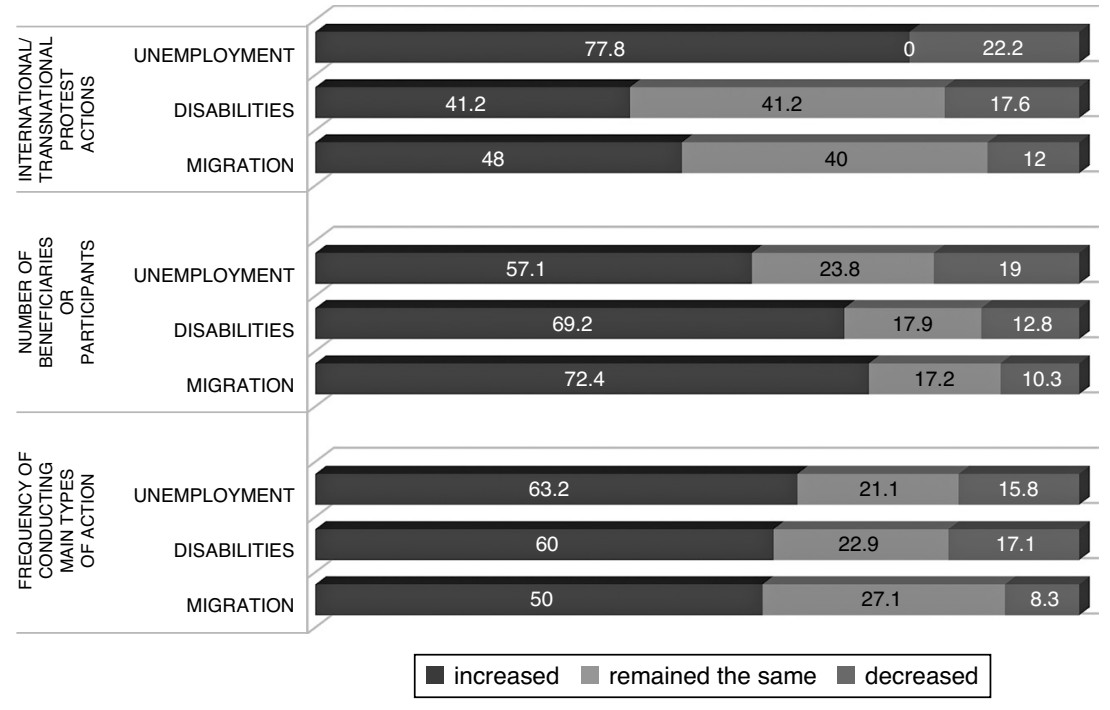

Figure 3.9 Experienced changes in the form of demand/need (protest, direct action, no. of beneficiaries), by field 


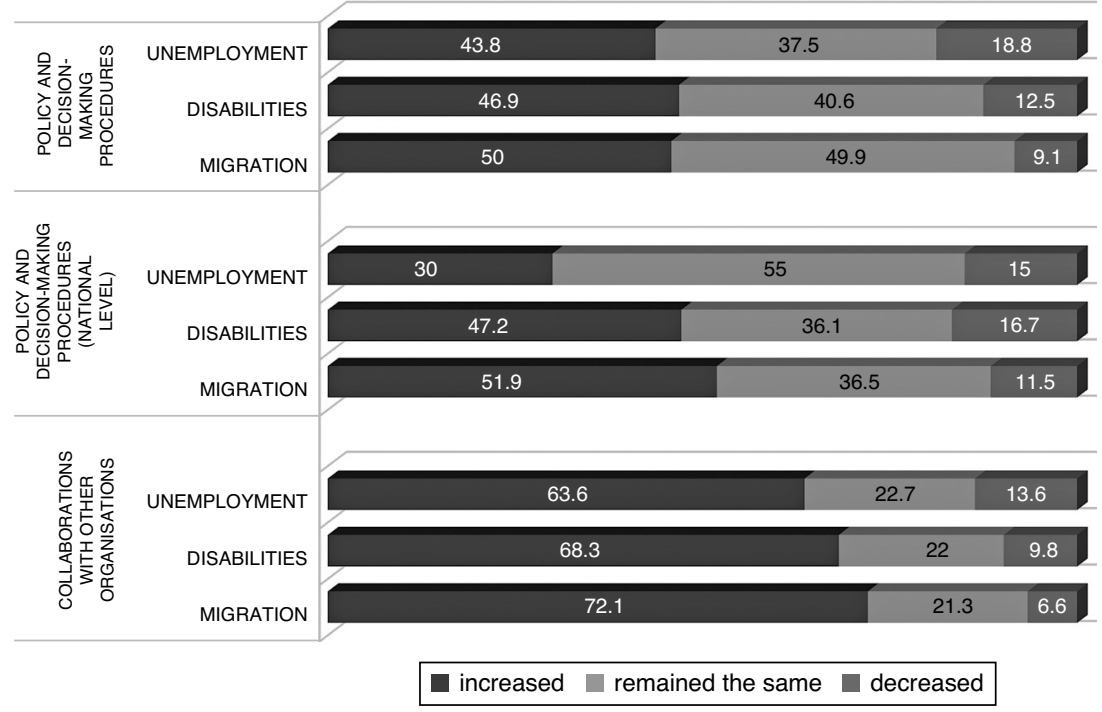

Figure 3.10 Experienced changes in policy outreach, participation and other collaborations, by field

order to meet these needs and engage in transnational protest in order to increase their effectiveness. Engagement in transnational protest actions and campaigns increased for the vast majority of the unemployment TSOs and for a significant part of TSOs from the other fields. This is an expected outcome (especially for the unemployment TSOs) as protest is a common strategy in times of austerity and increased inequalities. At the same time, more than half of the TSOs point out that the number of their beneficiaries increased, while only $10-20 \%$ declare that they support fewer people than they used to prior to the crisis period. As for the frequency of the conducted activities, approximately six out of ten TSOs, irrespective of their field, mentioned that they organised more actions compared to the pre-crisis period. The responses to these last two questions are a clear sign that both crises increased the number of beneficiaries or participants in need of support. Moreover, they demonstrate the reflexes of civil society in assisting those in need during times of increased inequalities.

Moving to TSO collaboration tactics shown in Figure 3.10, the crisis appears to be an opportunity for networking with similar organisations and groups. As the availability of the resources in periods of crises is limited, TSOs have to collaborate with other organisations in order to maintain their activities. Indeed, almost seven out of ten TSOs, regardless of their field, mentioned that they cooperated more with other organisations 
during the crisis period than they did in the past. The crises also increased TSO engagement in policy and decision making procedures at the national and supranational level. At the supranational level almost half of the TSOs mentioned that they have increased their participation in policy making procedures, while approximately four out of ten mentioned that they participate at the same level as always. Moving to the national-level decision making procedures, the situation is almost the same for TSOs in the migration and disability fields. In contrast to the unemployment TSOs, half of them mention that there is no change in participation and a third that they participate more than they did in the past.

\subsection{DISCUSSION AND CONCLUSION}

Our analysis of TSOs takes an integrated approach, as it was our attempt to better address their development through time and provide an enhanced understanding of their actions, obstacles, opportunities and constraints. Findings show that solidarity activities are widely diffused across Europe and are carried out by a wide network of active citizens, civil society groups and social movement organisations. However, the development of the organisational field of TSOs and the intensity of its activities depends strongly on both contextual and organisational factors. Citizens and civic groups tend to step up their efforts in contexts marked by crises and grievances, with their European activities being especially dependent on organisational capacities and resources.

With regard to the dynamism of the organisational field, our data portray a lively picture of civic solidarity across Europe, showing that transnational solidarity, which has its roots in the beginning of the twentieth century, has grown considerably in the recent period, seemingly trying to keep up with societal challenges within the European Union. Transnational solidarity organisations and groups are committed to confronting a number of problems and hardships such as poverty, social inequalities, exclusion and discrimination. They do so by committing to activities that address various sectors of our society including politics, the public sphere, the judicial system, and civil society. TSOs nevertheless remain rational decision makers "to achieve instrumental and cultural goals" (McAdam et al., 1988 in Carmin and Balser, 2002: 385). Furthermore, the evolution of organised transnational solidarity across fields and countries mirrors heightened grievances in times of economic crisis and austerity policies and the subsequent mobilisation of civic support and political protest.

The analysis of organisational capacities and contextual opportunities 
and constraints allows us to draw a number of lessons. First, citizen groups and social movement organisations operate mainly at the local level, thus responding to urgent needs and demands in their immediate environment. Additionally, these groups tend to cherish the grass-roots level as a primary focus of activity, more strictly linked to constituencies and more immediate in its accountability. This is not an indication that transnational solidarity is absent within the wider field of TSOs. The fact that most TSOs are of local scope leads to the proposition that European solidarity is mainly a question of cross-national cooperation between local groups (Tarrow, 1998; Mattoni and della Porta, 2014; Lahusen et al., 2018). This is known in movement studies as soft diffusion, or, in our understanding as soft transnationalism (see Chapter 8), when compared to the hard transnationalism of fixed and formal supra/transnational organisations. There might be indications that this soft form is more flexible in adapting to upcoming grievances, and more compatible with the advocatory grass-roots orientation of many movements. Further analyses are needed on the above, as well as on the sustainability of these civic efforts, and the circumstances under which they can and will prolong their work during times of extended insecurities and crises.

Second, solidarity organisations reach out beyond their national borders and they are also exposed to processes of Europeanisation (Monforte, 2009; della Porta and Caiani, 2009), which imply, to a certain degree, a scale shift from the local and national to the European level. However, this process is highly conditional on a number of factors, i.e. from organisational capacities to the use of external opportunities. TSO representatives report an intensification of their actions due to increased demand, particularly in meeting urgent needs, and to the broadening of vulnerability and the increase in beneficiary groups. Given that competition over scarce national funding is harsh, organisations are apparently turning their attention to European funding, which appears to be a more stable and reliable source of support allows for an expansion of their collaborations beyond national borders. Hence, the various crises affecting European countries seem to give impetus towards a Europeanisation of solidarity activism. Organisational features that would have been expected to predispose a scale shift, such as formality, established partnership with EU institutions, and the age of TSOs, do not seem to play a decisive role, given that also younger and more informal groups are actively engaged in cross-national solidarity.

Finally, it appears that European activities are driven by a specific understanding of solidarity. TSOs with transnational activism believe in a conception of solidarity that emphasises horizontal elements of mutualism and reciprocity. These TSOs are also more likely to engage in 
EU partnerships, while they are more contentious and political in terms of their action repertoires. In this sense, it seems as though transnational solidarity organisations are promoting an alternative vision of European solidarity that professes the idea of empowerment and cross-national cooperation at the grass-roots level. While TSOs call on governments and EU institutions to take responsibility for societal problems and crisesrelated grievances, they are at the same time voicing the need to construct and mobilise an active and critical citizenship across borders.

\section{NOTES}

1. Results presented in this chapter have been obtained within Work Package 2 of the project "European paths to transnational solidarity at times of crisis: Conditions, forms, role models and policy responses" (TransSOL). This project has received funding from the European Union's Horizon 2020 research and innovation programme under grant agreement No 649435. http://transsol.eu/. The diligence, enthusiasm and work of all the teams participating in Work Package 2, are gratefully acknowledged.

2. Qualitative data based on in-depth interviews were also used in TransSOL's Work Package 2; however, they are analysed in a related comparative volume (see Lahusen, Kousis and Zschache (eds), 2020, Palgrave) and are not used in this chapter.

\section{REFERENCES}

Ataç, I., Rygiel, K. and Stierl, M. (2016). Introduction: The Contentious Politics of Refugee and Migrant Protest and Solidarity Movements: Remaking Citizenship from the Margins. Citizenship Studies, 20(5): 527-44.

Baglioni, S. and Giugni, M. (eds) (2014). Civil Society Organisations, Unemployment and Precarity in Europe: Between Service and Policy. Basingstoke: Palgrave Macmillan.

Carmin, J. and Balser, D. B. (2002). Selecting Repertoires of Action in Environmental Movement Organizations: An Interpretive Approach. Organization \& Environment, 15(4): 365-88.

Davies, T. R. (2016). History of Transnational Voluntary Associations: A Critical Multidisciplinary Review. Voluntaristics Review, 1(4): 1-55.

della Porta, D. and Caiani, M. (2009). Social Movements and Europeanization. Oxford: Oxford University Press.

Edwards, B. and McCarthy, J. D. (2004). Resources and Social Movement Mobilization. In D. A. Snow, S. A. Soule and H. Kriesi (eds), The Blackwell Companion to Social Movements. Oxford: Blackwell, pp. 116-52.

Featherstone, D. (2013): Solidarity: Hidden Histories and Geographies of Internationalism, London: Zed Books.

Feischmidt, M., Pries, L. and Cantat, C. (eds) (2019). Refugee Protection and Civil Society in Europe. Basingstoke: Palgrave Macmillan.

Freeman, J. (1979). Resource Mobilization and Strategy: A Model for Analyzing Social Movement Organization Actions. In M. N. Zald and J. D. McCarthy (eds), 
The Dynamics of Social Movements: Resource Mobilization, Social Control, and Tactics. Cambridge, MA: Winthrop, pp. 167-89.

Hande, M. J. and Kelly, C. (2015). Organizing Survival and Resistance in Austere Times: Shifting Disability Activism and Care Politics in Ontario, Canada. Disability \& Society, 30(7): 961-75.

Hirsch, E.L. (1986). The Creation of Political Solidarity in Social Movement Organizations. The Sociological Quarterly, 27(3): 373-87.

Hwang, H. and Powell, W. W. (2009). The Rationalization of Charity: The Influences of Professionalism in the Nonprofit Sector. Administrative Science Quarterly, 54(2): 268-98.

Imig, D. and Tarrow, S. (1999). The Europeanization of Movements? A New Approach to Transnational Contention. In D. della Porta, H. Kriesi and D. Rucht (eds), Social Movements in a Globalizing World. London: Palgrave Macmillan, pp. 112-33.

Jenkins, J. C. (1983). Resource Mobilization Theory and the Study of Social Movements. Annual Review of Sociology, 9(1): 527-53.

Kanellopoulos, K., Duru, D., Zschache, U., Loukakis, A., Kousis, M. and Trenz, H.-J. (2018). Transnational Solidarity to Refugees in Greece, Germany and Denmark. Paper presented at the TransSOL Final Conference, 16-17 May 2018, Brussels.

Kousis, M. and Eder, K. (2001). EU Policy-Making, Local Action, and the Emergence of Institutions of Collective Action. In Environmental Politics in Southern Europe. Dordrecht: Springer, pp. 3-21.

Kousis, M., Giugni, M. and Lahusen, C. (2018). Action Organization Analysis: Extending Protest Event Analysis Using Hubs-Retrieved Websites. American Behavioral Scientist, 62(6): 739-57.

Kousis, M., Kalogeraki, S. and Cristancho, C. (2018). Alternative Action Organizations during Hard Economic Times: A Comparative European Perspective. American Behavioral Scientist, 62(6): 733-8.

Kousis, M. and Paschou, M. (2017). Alternative Forms of Resilience: A Typology of Approaches for the Study of Citizen Collective Responses in Hard Economic Times. Partecipazione e Conflitto, 10(1): 136-68.

Kousis, M., Paschou, M. and Loukakis, A. (2020). Innovative Transnational Solidarity Organizations in Europe during the economic and refugee crises: From adaptive to autonomous? Under review, Sociological Research Online.

Kriesi, H., Tresch, A. and Jochum, M. (2007). Going Public in the European Union: Action Repertoires of Western European Political Actors. Comparative Political Studies, 40: 48-73.

Lahusen, C. (2013). The Protests of the Unemployed in France, Germany and Sweden (1994-2004): Protest Dynamics and Political Contexts. Social Movement Studies, 12(1): 1-22.

Lahusen, C., Kousis, M., Zschache, U. and Loukakis, A. (2018). European Solidarity in Times of Crisis: Comparing Transnational Activism of Civic Organisations in Germany and Greece. Österreichische Zeitschrift für Soziologie, 43(1): 173-97.

Loukakis, A. and Maggini, N. (2020). Transnational activism for global crises: resources matter! Comparison of Transnational Solidarity Organisations in eight European countries. Under review, Sociological Research Online.

Mattoni, A. and della Porta, D. (2014). Adapting Theories on Diffusion and Transnational Contention through Social Movements of the Crisis: Some 
Concluding Remarks. In D. della Porta and A. Mattoni (eds), Spreading Protests: Social Movements in Times of Crisis. Colchester: ECPR Press, pp. 277-92.

McAdam, D. (1983). Tactical Innovation and the Pace of Insurgency. American Sociological Review, 48: 735-54.

McAdam, D., McCarthy, J. D. and Zald, M. N. (1988). Social Movements. In N. J. Smelser (ed.), Handbook of Sociology. Newbury Park, CA: Sage, pp. 695-737.

McCallum, J. K. (2013). Global Unions, Local Power: The New Spirit of Transnational Labour Organizing. Ithaca, NY and London: ILR/Cornell University Press.

McCarthy, J. D., Britt, D. W. and Wolfson, M. (1991). The Institutional Channeling of Social Movements in the Modern State. Research in Social Movements, Conflicts and Change, 13: 45-76.

McCarthy, J. D. and Wolfson, M. (1996). Resource Mobilization by Local Social Movement Organizations: Agency, Strategy, and Organization in the Movement against Drinking and Driving. American Sociological Review, 61(6): 1070-88.

McCarthy, J. D. and Zald, M. N. (1977). Resource Mobilization and Social Movements: A Partial Theory. American Journal of Sociology, 82(6): 1212-41.

Monforte, P. (2009). Social Movements and Europeanization Processes: The Case of the French Associations Mobilizing Around the Asylum Issue. Social Movement Studies, 8(4): 409-25.

Moulaert, F. and Ailenei, O. (2005). Social Economy, Third Sector and Solidarity Relations: A Conceptual Synthesis from History to Present. Urban Studies, 42(11): 2037-53.

Pape, U., Chaves-Avila, R., Benedikt, J., Petrella, F., Pielinski, B. and SavallMorera, T. (2016). Working Under Pressure: Economic Recession and Third Sector Development in Europe. International Journal of Sociology and Social Policy, 36(7/8): 547-66.

Passy, F. (2001): Political Altruism and the Solidarity Movement: An Introduction. In M. Giugni and F. Passy (eds), Political Altruism? Solidarity Movements in International Perspective. Boston, MA: Rowman \& Littlefield, pp. 3-25.

Piven, F. F. and Cloward, R. A. (1977). Poor People's Movements: How they Succeed and How they Fail. New York: Vintage.

Raffo, D. M., Clark, L. A. and Arik, M. (2016). Strategic Responses of NonProfit Organizations to the Economic Crisis: Examining Through the Lenses of Resource Dependency and Resourced-Based View Theories. Academy of Strategic Management Journal, 15(1): 48-70.

Ruzza, C. and Bozzini, E. (2008). Organised Civil Society and European Governance: Routes of Contestation. European Political Science, 7(3): 296-303.

Salamon, L., Geller, S. L. and Spence, K. L. (2009). Impact of the 2007-2009 Economic Recession on Nonprofit Organizations. Illinois Business Law Journal, 9(3) (online), https://publish.illinois.edu/illinoisblj/2009/09/20/the-impact-of-the -financial-crisis-on-nonprofits/.

Sanchez Salgado, R. (2017). Europeanization of Civil Society Organizations in Times of Crisis? Exploring the Evolution Grant-Seeking Strategies in the EU Multi-Level System. European Politics and Society, 18(4): 511-28.

Scipes, K. (ed.) (2016). Building Global Labor Solidarity in a Time of Accelerating Globalization. Chicago, IL: Haymarket Books.

Soldatic, K. and Grech, S. (2014). Transnationalising Disability Studies: Rights, Justice and Impairment. Disability Studies Quarterly, 34(2), http://dx.doi.org/ 10.18061/dsq.v34i2.4249. 
Staggenborg, S. (1988). The Consequences of Professionalization and Formalization in the Pro-Choice Movement. American Sociological Review, 53: 585-606.

Tarrow, S. (1998). Power in Movement: Social Movements and Contentious Politics. New York: Cambridge University Press.

TransSOL (2016). Integrated Report on Reflective Forms of Transnational Solidarity. Deliverable 2.1. Available at https://transsol.eu/files/2016/12/Integrated-Reporton-Reflective-Forms-of-Transnational-Solidarity.pdf.

Uba, K. and Kousis, M. (2018). Constituency Groups of Alternative Action Organizations During Hard Times: A Comparison at the Solidarity Orientation and Country Levels. American Behavioral Scientist, 62(6): 816-36.

Warleigh, A. (2001). 'Europeanizing' Civil Society: NGOs as Agents of Political Socialization. Journal of Common Market Studies, 39(4): 619-39.

Zschache, U., Theiss, M. and Paschou, M. (2020). What is solidarity about? Views of transnational solidarity activists in Germany, Poland and Greece. Under review, Sociological Research Online. 